\title{
Polymer Based Composite and Hybrid Materials for Wind Power Generation
}

\author{
N. M. Chikhradze $e^{1, a}$, F.D. Marquis ${ }^{2, b}$, L..A. Japaridze ${ }^{1, c}$, G. S. Abashidze ${ }^{1, a}$ and L. M. \\ Okujava $^{3, d}$ \\ ${ }^{1}$ G. Tsulukidze Mining Institute, Tbilisi, Georgia \\ ${ }^{2}$ Naval Postgraduate School, Wayne Meyer Institute of Systems Engineering, Monterey, CA, \\ U.S.A. \\ ${ }^{3}$ K. Zavriev Institute of Structural Mechanics and Seismic Stability, Tbilisi, Georgia \\ a chikhradze@mining.org.ge, ${ }^{b}$ fdmarquis@nps.edu, ${ }^{c}$ levan@grdf.ge, ${ }^{d}$ leonideokujava@gmail.com
}

Keywords: Hybrid polymer composite (HPC), glass fiber (GF), carbon fiber (CF), basalt fiber $(\mathrm{BF})$, vacuum infiltration (VI), Prepreg technology (PrT), strength and deformability HPC

Abstract: In recent years considerable attention has been dedicated to renewal power sources, such as wind power. This work was carried out in order to develop a small wind turbine of $1-10 \mathrm{~kW}$ power generation capability. This wind turbine is designed to be energetically more efficient by $30-$ $50 \%$ and having a lesser specific cost (by 25-30\%). This work focused on the development of composite materials for application on the blades in the wind generator. In this paper we present the results of the research work done on the development of flexible technology for the fabrication matrix-epoxy resin based hybrid composites, reinforced with carbon, basalt and glass fibers. These new composite and hybrid materials were fabricated using epoxy matrixes. These matrices were reinforced with basalt and carbon fibers of different content and strengthened by mullite-like crystals. The basalt fibers for composite reinforcing were prepared from raw materials, with chemical composition: $\mathrm{SiO}_{2}-15.3 \%$; $\mathrm{CaO}-10.8 \%$; $\mathrm{Na}_{2} \mathrm{O}-4.2 \%$; $\mathrm{MgO}-8.8 \%$; $\mathrm{Fe}_{2} \mathrm{O}_{3}-12.1 \%$; $\mathrm{MnO}-$ $0.7 \%$; $\mathrm{TiO}_{2}-0.7 \%$. The properties of new composites developed depend on the content and architecture of reinforcing components and are: tensile strength-(0.012-1.590)GPa; compression strength-(0.078-0.656)GPa; modulus of elasticity-(8.4-162.9)GPa; Poisson ratio-(0.015-0.559). The variation of strength and elastic characteristics under tension and compression of the new composites are presented.

\section{Introduction}

The wind-power engineering is a priority area of energy generation due to its resource-saving and ecologically safe. The power cost primary is determined substantially by basic power element blades. At present hybrid fibers (carbon, glass) are mainly used for fabrication of the blades [1], whereas the works for reinforcing of epoxy matrices with basalt and other fibers are known [2]. The task of cost reduction may be solved through application of the less expensive materials in comparison with carbon fibres. For blade creation an application of new composite hybrid material is suggested on the basis of epoxy matrixes, strengthened by mullite-like crystals, as well as - on combinations of high-strength and high-modulus basalt and carbon fibers. Basalt reinforcing element of a composite was prepared on the basis of Georgian raw materials. The problem consists in a partial or total substitution of expensive carbon fiber in the material. An application of hybrid reinforcing fibers and of strengthened matrix will permit a considerable reduction of the blade cost without significant loss of physical-mechanical properties of the material.

\section{Experimental Procedures}

According to recommendations of investigators of wind turbines at preparation of shells of blade the carbon fibers should be arranged at $-20^{\circ}$ angle to axis of blade, and glass ones - perpendicular to them $[3,4,5]$.

At preparation of a spar reinforcing fibers were arranged parallel and at $+45^{\circ}$ angle to $\mathrm{X}$-axis. In Fig. 1, Fig. 2 the structure of composites destined accordingly for shell and spar of blade is shown. 
The following methods of composites preparation are used: vacuum impregnation of reinforcing components (VI), layer-by-layer lining and forming of prepregs (PrT). In first case socalled mean of vacuum sack is used. At prepreg technology layers of preliminary impregnated belt successively observing the given orientation are being collected into package and pressed in thermal chamber.

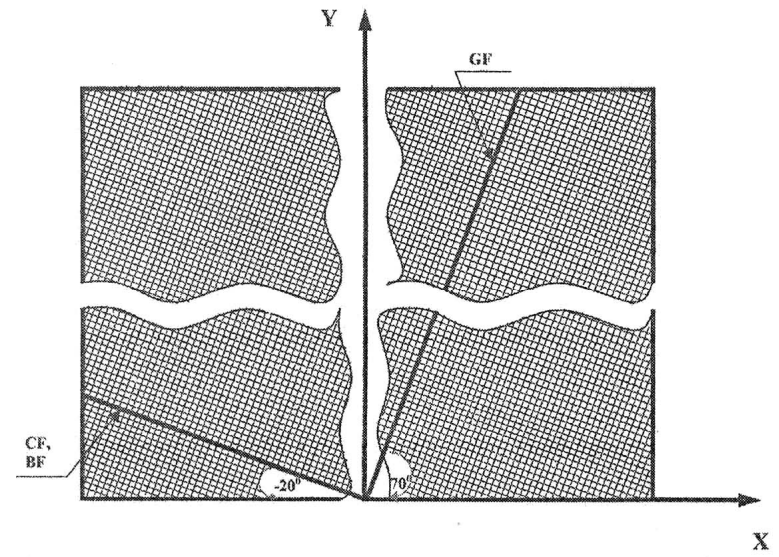

Figure 1 Scheme of arrangement of reinforcing elements in composite destined for shell

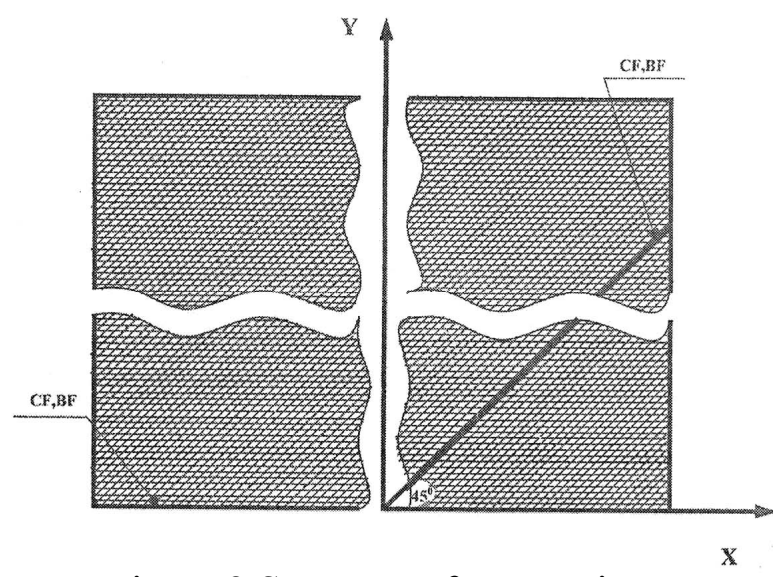

Figure 2 Structure of composite destined for spar.

The collected package is formed according to special regime. Some series of composites with the above-mentioned structures and following contents of reinforcing components are prepared:

Series A: Relation GF : $\mathrm{CF}=0,3: 0,7$ (according to mass)

A-1 Technology -VI. Structure: 3 layers Weft-Knitted Fabric (WKF), 4 layers GF.

A-2 Technology - PrT. Structure: 7 layers CF, 4 layers GF.

Series B: Relations GF: CF are the same.

Technology - PrT. Structure: 7 layers CF, 2 layers BF, 4 layers GF (BF is $20 \%$ of total mass of fibers).

Series C: The same as in B series is, only BF content is increased up to $40 \%$.

Series D: The same as in series $\mathrm{C}$ is, only the matrix is strengthened with mullite-similar additive in $3 \%$ amount of epoxy resin mass.

Series E: Technology - PrT. Structure: high-resistant and high-modular carbon rovings are placed parallel and at $+45^{\circ}$ angle to $\mathrm{X}$ axis.

Series F: The same as in series $\mathrm{E}$ is. CF is replaced with $20 \% \mathrm{BF}$.

F-1 Technology: VI. F-2 Technology: PrT.

Series G: The same as in E series is. CF is replaced with $40 \% \mathrm{BF}$.

Composites of A ...D and E... G series are prepared according to schemes shown in Fig. 1, Fig. 2 and are destined for shell and spar of blade.

The strength and elasticity characteristics of composites are defined by means of universal German machine FRZ-100 equipped with deformation meter. To define the Poisson's ratio the resistance strain gauges pasted on a middle of working part on its both sides in longitudinal and transversal directions are used. Taking into account the relaxational character of mechanical properties of composites the definite time regime of tests is observed - velocity of mutual movement of machine's working elements is $20 \mathrm{~mm} / \mathrm{min}$.

\section{Results and Discussion}

First of all it should be noticed the advantages of the autoclave method of composite forming are revealed in comparison with other methods, in particular "wet" method when the impregnation of reinforced components with the binder, and material forming are accomplished simultaneously. These advantages are apparently stipulated by practically full wetting of fiber with the binder, and strict regulation of its content in a composite at preliminary impregnation and preparation of semifinished items - prepreg. Data in Table 1 are the proof of the mentioned advantages of autoclave method of hybrid composites. Here and next the following conditional notations are 
accepted: $\sigma$ - limit of strength; $\mathrm{E}$ - elasticity modulus; $\varepsilon$ - relative deformation; $\mu$ - Poisson's ratio; lower indexes; $\mathrm{t}$ - tension; c - compression; upper indexes; $\|$ - in direction parallel to $\mathrm{X}$ axis; $\perp-$ in direction perpendicular to $\mathrm{X}$ axis.

Table 1 Strength and elasticity characteristics of composites prepared by different methods

\begin{tabular}{|c|c|c|c|c|c|c|c|c|c|}
\hline \multirow[b]{2}{*}{ Method } & \multicolumn{8}{|c|}{ Strength- and elasticity characteristics, GPa } & \multirow[b]{2}{*}{ Remarks } \\
\hline & $\sigma_{t}^{\amalg}$ & $\sigma_{t}^{\perp}$ & $\sigma_{C}^{\amalg}$ & $\sigma_{C}^{\perp}$ & $E_{t}^{\amalg}$ & $E_{t}^{\perp}$ & $E_{C}^{\amalg}$ & $E_{C}^{\perp}$ & \\
\hline VI & 0,102 & 0,111 & 0,167 & 0,139 & 32,5 & 8,4 & 21,8 & 12,8 & \multirow{2}{*}{$\begin{array}{l}\text { Composites } \\
\text { for shell }\end{array}$} \\
\hline PrT & 161 & 0,1 & 0,352 & 0,2 & 33,9 & 17,6 & 40,8 & 16,4 & \\
\hline VI & 0,748 & 0,009 & 0,483 & 0,078 & 131,2 & 13,9 & 123 & 8,8 & \multirow{2}{*}{$\begin{array}{l}\text { Composites } \\
\text { for spar }\end{array}$} \\
\hline PrT & 1,590 & 0,012 & 0,656 & 0,098 & 162,9 & 10,9 & 131 & 17,8 & \\
\hline
\end{tabular}

Influence of substitution of a part of carbon fiber for basalt and of injection of mullite-similar powder in epoxy matrix on the strength- and elasticity characteristics of composites is shown in Figs. 3 and 4.

The mullite-similar filler of epoxy matrix increases as a whole the strength and elasticity modulus of composites for tension accordingly by 20 and 14\%. The increases of the strength and elasticity modulus for compression are 13 and $80 \%$ (Fig. 4). At the same time is should be noted that at 20 and $40 \%$ substitution of carbon fiber for basalt gives approximately the same deterioration of the strength- and elasticity characteristics (Fig. 3). So if such deterioration of mechanical properties of composites is acceptable at solution of concrete technical task, expensive carbon fiber can be substituted for $20-40 \%$ incomparably cheaper basalt one.

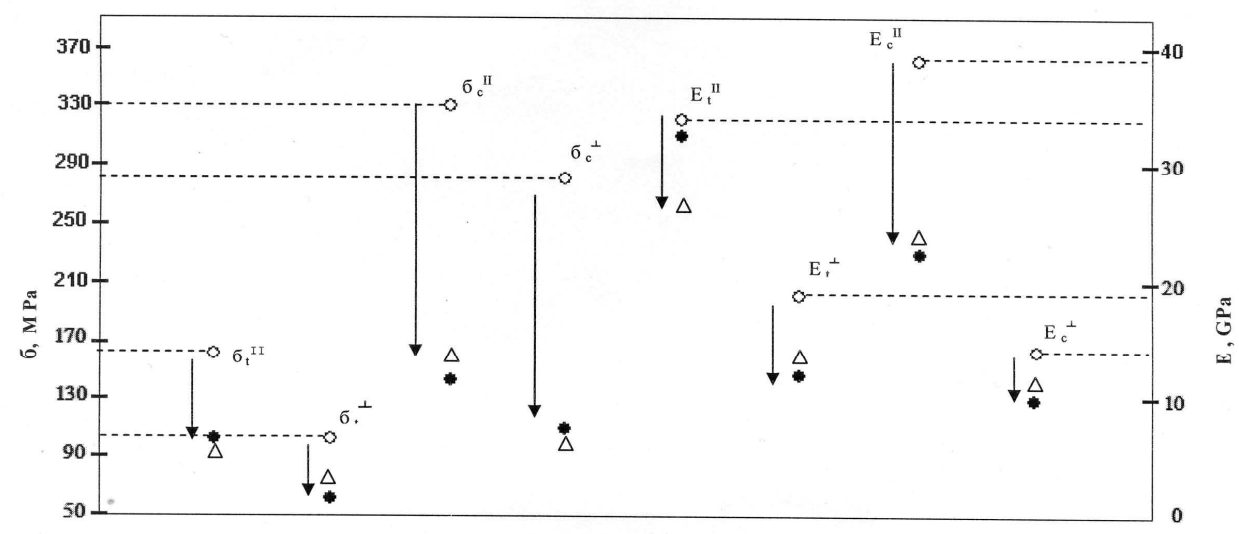

Figure 3 Lowering of strength and elasticity characteristics of composites at substitution of a part of carbon fiber for basalt: 0 -series A-2; $*$ series B; $\Delta$-series C.

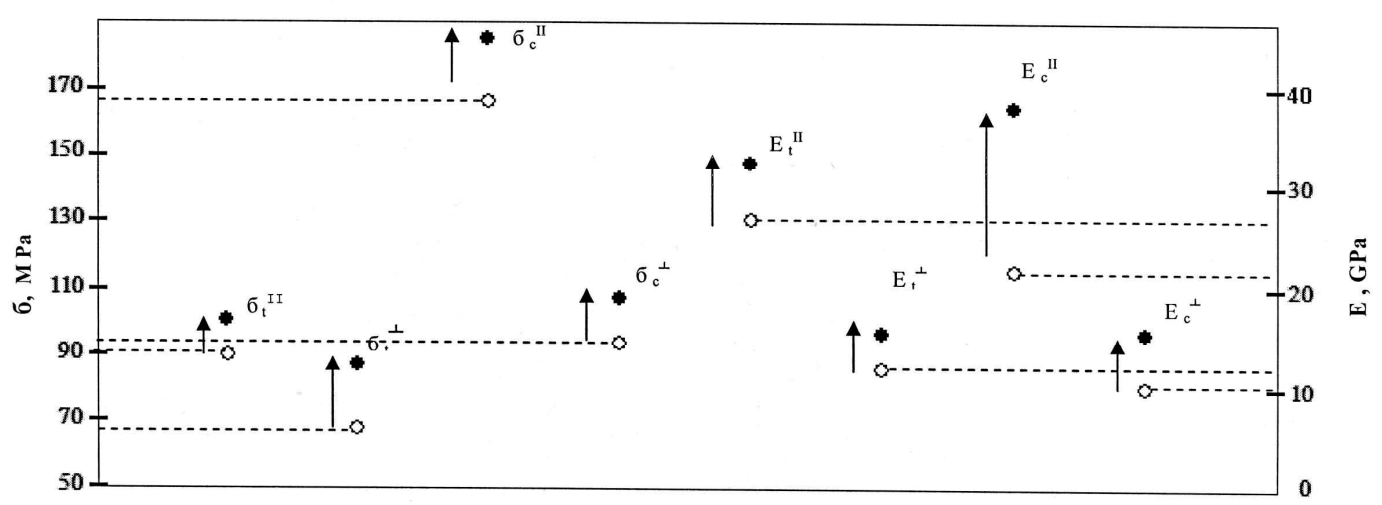

Figure 4 Increasing of strength and elasticity characteristics of composites as a result of reinforcement of matrix with mullite-similar addition 0 - series $C ; *-$ series D 
According to data given in Fig. 3, substitution of carbon reinforcing structures for basalt ones leads to the maximal drop of strength and elasticity modulus on tension accordingly by $46 \%$ and $32 \%$. In the case of compression such a drop is more perceptible and is equal to $54 \%$ and $40 \%$. In separate cases depending on fiber orientation, the drop of strength and deformation characteristics is not substantial.

Values of relative deformations and Poisson's ratio necessary for calculation of constructions design with applications of the above-mentioned composites are given in Table 2.

Table 2 Values of Relative Deformations and Poisson's ratios of Composites

\begin{tabular}{|c|c|c|c|c|c|c|}
\hline \multirow{2}{*}{ Series } & \multicolumn{4}{|c|}{ Relative Deformations, $\%$} & \multirow{2}{*}{$\mu^{\amalg}$} & \multirow{2}{*}{$\mu^{\perp}$} \\
\hline & $\varepsilon_{t}^{\amalg}$ & $\varepsilon_{t}^{\perp}$ & $\varepsilon_{C}^{\amalg}$ & $\varepsilon_{C}^{\perp}$ & & \\
\hline A & 1,20 & 1,49 & 1,46 & 0,37 & 0,491 & 0,190 \\
\hline B & 0,92 & 0,85 & 2,04 & 1,55 & 0,559 & 0,369 \\
\hline $\bar{C}$ & 0,75 & 0,85 & 1,45 & 1,82 & 0,432 & 0,284 \\
\hline $\mathrm{D}$ & 0,34 & 0,76 & 1,08 & 0,8 & 0,461 & 0,218 \\
\hline $\mathrm{E}$ & 0,72 & 0,38 & 0,71 & 0,40 & 0,372 & 0,021 \\
\hline $\mathrm{F}$ & 0,64 & 0,27 & 0,72 & 1,65 & 0,297 & 0,015 \\
\hline $\mathrm{G}$ & 0,67 & 0,32 & 0,68 & 0,98 & 0,311 & 0,019 \\
\hline
\end{tabular}

\section{Conclusions}

1. The substitution of $20 \%-40 \%$ high-strength and high-modulus carbon fiber for high-strength basalt in hybrid polymer composite provides an acceptable reduction of strength and stiffness in tension and compression allowing its use in wind power turbine blade applications.

2. Injecting fine-dispersed powder-reinforcers in epoxy matrix composites improves the strengthand deformation characteristics of these composites. The degree of effectiveness of these reinforcers is specific to the matrix.

3. The results obtained for tension and compression tests shown the feasibility of application of hybrid composites in wind turbine blades. For a complete evaluation of these hybrid materials their behavior in cyclic bending and torsion should also be investigated.

\section{Acknowledgement}

The authors of this paper gratefully acknowledge the financial support from STCU (Grant №3631).

\section{References}

[1] P. Bronds, H. Lilhopt, A. Lystrup: Annual Review of Materials Research, vol. 35 (2005), pp. 505-538.

[2] J.M. Park, W.G. Shin, D.J. Yoon: Composites Science and Technology, v. 59, 1.3 (February 1999), pp. 355-370.

[3] D.A. Griffin: SAND 2002-1879, vol. I, Albuquerquer, NM: Sandia National Laboratories (2002).

[4] D.A. Griffin, T.D. Aswill: Proceedings of the 48 International SAMPE Symposium and Exhibition. Long Beach, CA (2003).

[5] D.A. Griffin: SAND 2004-0073, vol. II, Sandia National Laboratories (2004). 